\title{
PEMANFAATAN MEDIA POWER POINT DALAM PEMBELAJARAN FISIKA DENGAN PENDEKATAN KONSTRUKTIVISME
}

\author{
Badrul Wajdi \\ Pendidikan Fisika Jurusan Pendidikan MIPA STKIP Hamzanwadi Selong \\ Email: badrulwajdi82@gmail.com
}

\begin{abstract}
Abstrak
Penelitian ini bertujuan untuk mengetahuipengaruh pemanfaatan media power point dalam pembelajaran fisika dengan pendekatan konstruktivisme terhadap prestasi belajar siswa. Materi pelajaran yang dikaji dalam penelitian ini adalah zat dan wujudnya.Tempat pelaksanaan penelitian di SMP Negeri 1 Wanasabapada semester Ganjil tahun pembelajaran 2013/2014. Jenis penelitian ini adalah penelitian eksperiman dengan populasi seluruh siswa kelas VII SMP Negeri 1 Wanasaba yang terdiri dari 7 kelas dan sampelnya adalah kelas $\mathrm{VII}_{2}$ dan $\mathrm{VII}_{3}$ yang diperoleh dengan cara cluster random sampling.Variabel bebas dalam penelitian ini adalah media power point dan variabel terikat dalam penelitian ini adalah prestasi belajar fisika siswa. Teknik pengumpulan data dilakukan dengan menggunakan metode tes. Hasil analisis data menunjukkan bahwa pada kelas eksperimen didapatkan harga $t_{\text {hitung }}$ sebesar 1,76 sedangkan nilai $t_{\text {tabel }}$ sebesar 1,684 pada taraf signifikansi 5\%.Jadi nilai $t_{\text {hitung }}$ lebih besar dibandingkan dengan nilai $t_{\text {tabel }}$ $\left(t_{\text {hitung }}>t_{\text {tabel }}\right)$ sehingga dapat disimpulkan bahwa terdapat pengaruh pemanfaatan media power point dalam pembelajaran fisika dengan pendekatan konstruktivisme terhadap prestasi belajar siswa.
\end{abstract}

Kata Kunci: Power Point, Prestasi Belajar, Konstruktivisme

\section{PENDAHULUAN}

Belajar merupakan suatu proses, suatu kegiatan dan bukan suatu hasil dan tujuan. Belajar bukan hanya mengingat, akan tetapi lebih luas dari itu, yakni mengalami hasil belajar bukan suatu penguasaan hasil latihan melainkan pengubahan kelakuan. Proses belajar-mengajar merupakan inti dari proses pendidikan secara keseluruhan dengan guru sebagai pemegang peranan utama. 
Peristiwa belajar-mengajar banyak berakar pada berbagai pandangan dan konsep. Proses belajar-mengajar mempunyai makna dan pengertian yang lebih luas dari pada pengertian mengajar. Dalam proses belajarmengajar tersirat adanya satu kesatuan kegiatan yang tak terpisahkan antara siswa yang belajar dan guru yang mengajar.. Oemar Hamalik (2001) menjelaskan bahwa belajar adalah modifikasi atau memperteguh kelakuan melalui pengalaman (learning is defined as the modification or strengthening of behavior through experiencing).

Dalam pandangan teori psikilogi kognitif terdapat satu bentuk pembelajaran yaitu pembelajaran konsrtuktivisme. Teori ini berpandangan bahwa pengetahuan anak atau siswa sangat berdampak pada proses pendidikan, dalam pembelajaran konstruktivisme pengetahuandiperoleh siswa oleh siswa sendiri dan guru berperan sebagai fasilitator dalam menciptakan belajar yang kondusif dalam kelas. Tujuan pembelajaran ini adalah siswa memiliki kemampuan dalam menemukan, memahami, dan menggunakan informasi atau pengetahuan yang dipelajari.

Belajar menurut teori konstruktivisme menurut Budiningsih (2005) adalah suatu proses pembentukan pengetahuan. Pembentukan ini harus dilakukan oleh peserta didik sendiri.Maka peserta didik harus aktif melakukan kegiatan, aktif berfikir, menyusun konsep dan memberi makna sesuatu yang dipelajarinya.Maka para guru berperan untuk menciptakan lingkungan yang memungkinkan terjadinya belajar.Artinya mereka perlu mengatur lingkungan agar peserta didik termotivasi untuk belajar.

Dalam menyampaikan suatu pelajaran, tidak semudah yang dibayangkan, seorang guru harus mampu menyajikan materi pelajaran.Salah satu bentuk penyajian materi pelajaran yang biss dilakukan oleh guru adalah menggunakan media. Oemar Hamalik (2001) menjelaskan bahwa pemakaian media pembelajaran dalam proses belajar mengajar dapat membangkitkan keinginan dan minat yang baru, membangkitkan motivasi dan 
rangsangan kegiatan belajar, dan bahkan membawa pengaruh-pengaruh psikologis terhadap siswa.

Media adalah wahana penyalur pesan atau informasi belajar Azhar Arsyad (2011) mengatakan peran media dalam proses pembelajaran diantaranya adalah: (1) dapat mengatasi perbedaan pribadi peserta didik; (2) dapat mengatasi verbalisme; (3) Membangkitkan minat belajar peserta didik sehingga merangsang keinginan untuk belajar; (4) Dapat mendorong rasa ingin tahu peserta didik; dan (5) Dapat memperbaiki keterbatasan waktu dan tempat".

Mata pelajaran fisika memiliki peran untuk mengembangkan sikap dan pola pikir ilmiah, logis dan rasional dalam kehidupan sehari-hari. Pembelajaran fisika dalam proses pembelajaran didalam kelas dapat disajikan menggunakan media sebagai alat untuk membantu guru dan siswa. Media tersebut dapat berupa powert point berbasis audio visual.

Berdasarkan uraian tersebut, maka topik kajian ini berkaitan dengan pemanfaatan peneliti tertarik ingin melakukan penelitian dengan judul pemanfaatan media power point dalam pembelajaran fisika dengan pendekatan konstruktivisme

Tujuan yang ingin dicapai dalam kajian ini adalah untuk mengetahui pengaruh pemanfaatan media power point dalam pembelajaran fisika dengan pendekatan konstruktivismeterhadap prestasi belajar fisika siswa pada materi zat dan wujudnya.

\section{METODE}

Penelitian ini dilaksanakan di SMP Negeri 1 Wanasaba Kecamatan Wanasaba Kabupaten Lombok Tmur Provinsi Nusa Tenggara Barat pada semester Ganjil tahun pembelajaran 2013/2014. Populasi dalam penelitian ini adalah seluruh siswa-siswi kelas VII SMP Negeri 1 Wanasaba, Teknik pengambilan sampel dalam penelitian ini diambil dengan teknik cluster random sampling. Sehingga sampel penelitian adalah siswa pada kelas $\begin{array}{lllll}\mathrm{VII}_{2} \text { dan } & \mathrm{VII}_{3} & \mathrm{SMP} & \text { Negeri } & 1\end{array}$ Wanasaba.

Penelitian ini tergolong jenis penelitian eksperimen. Variabel bebas dalam penelitian ini adalah 
Badrul Wajdi - Pemanfaatan Media Power Point ...

pembelajaran konstruktivisme

menggunakan media powert point dan

Variabel terikatnya adalah prestasi belajar fisika siswa kelas VII SMP Negeri 1 Wanasaba.

Instrumen dalam penelitian ini ada dua macam instrumen yaitu, instrumen pelaksanaan pembelajaran dan instrumen pengambilan data. Instrumen pelaksanaan pembelajaran yang digunakan dalam penelitian ini adalah silabus dan RPP.Instrumen pengambilan data yang akan digunakan adalah berupa tes prestasi belajar. Sebelum instrumen digunakan maka perlu dilakukan uji coba instrumen yang bertujuan untuk mengetahui validitas instrumen, reliabilitas instrument, tingkat kesukaran, dan daya pembeda

Data yang diperoleh dalam penelitian ini akan dianalisis untuk membuktikan hipotesis penelitian. Sebelum dilakukan analisis data terlebih dahulu di lakukan uji prasyarat analisis yaitu uji normalitas data dan uji homogenitas data. Uji normalitas data dalam penelitian ini menggunakan rumus Chi-kuadrat sedangkan uji homogenitas yang digunakan adalah uji bartlet.
Adapun hipotesis yang diajukan dalam penelitian ini adalah: $\mathrm{H}_{0}$ berbunyi tidak ada pengaruh pemanfaatan media power point dalam pembelajaran fisika dengan pendekatan konstruktivisme terhadap prestasi belajar fisika siswa pada materi zat dan wujudnya dan $\mathrm{H}_{\mathrm{a}}$ berbunyi Ada pengaruh pemanfaatan media power point dalam pembelajaran fisika dengan pendekatan konstruktivisme terhadap prestasi belajar fisika siswa pada materi zat dan wujudnya.

Untuk membuktikan hipotesis tersebut digunakan uji t yaitu

$$
t=\frac{\bar{X}_{1}-\bar{X}_{2}}{\sqrt{\frac{\left(n_{1}-1\right) s_{1}^{2}+\left(n_{2}-1\right) s_{2}^{2}}{n_{1}+n_{2}-2}\left(\frac{1}{n_{1}}+\frac{1}{n_{2}}\right)}}
$$

Keterangan

$\overline{x_{1}}=$ Rata-rata prestasi kelas eksperimen

$\overline{x_{2}}=$ Rata-rata prestasi siswa kelas kontrol

$n_{1}=$ Jumlah siswa kelas eksperimen

$n_{2}=$ Jumlah siswa kelas kontrol

$S_{1}{ }^{2}=$ Standar deviasi kelas eksperimen

$S_{2}{ }^{2}=$ Standar deviasi kelas kontrol

Kriteria: 
$\mathrm{H}_{\mathrm{o}}$ diterima jika :- $\mathrm{t}_{\text {tabel }} \leq \mathrm{t}_{\text {hitung }} \leq \mathrm{t}_{\text {tabel }}$

$\mathrm{H}_{\mathrm{a}}$ diterima jika :

$\mathrm{t}_{\text {hitung }}<-\mathrm{t}_{\text {tabel }}$ atau $\mathrm{t}_{\text {hitung }}>\mathrm{t}_{\text {tabel }}$

\section{HASIL DAN PEMBAHASAN}

Penelitian ini menggunakan dua jenis media, media power point pada kelas eksperimen dan media konvensional pada kelas kontrol..

Deskripsi data hasil penelitian dapat dilihat pada tabel 1. Untuk memperjelas hasil eksperimen dan kontrol dapat dilihat pada gambar 1 dan gambar 2.

Tabel 1. Data post-test prestasi belajar

\begin{tabular}{|c|c|c|c|c|c|}
\hline Kelas & Jml Siswa & Nilai max & Nilai min & Rata-rata & $\begin{array}{l}\text { Stad. } \\
\text { Deviasi }\end{array}$ \\
\hline Post-test Kontrol & 25 & 85 & 45 & 67,04 & 12,378 \\
\hline Post-test Eksperimen & 25 & 95 & 55 & 74,52 & 12,272 \\
\hline
\end{tabular}

Tabel 2. Distribusi Frekuensi Kelas Eksperimen

\begin{tabular}{|c|c|c|}
\hline Interval Nilai & Titik Tengah & Frekuensi \\
\hline $55-61$ & 58 & 5 \\
\hline $62-68$ & 65 & 3 \\
\hline $69-75$ & 72 & 7 \\
\hline $76-82$ & 79 & 4 \\
\hline $83-89$ & 86 & 4 \\
\hline $90-96$ & 93 & $\mathbf{2 5}$ \\
\hline \multicolumn{2}{|c|}{ Jumlah } \\
\hline
\end{tabular}

Sebelum hipotesis dalam data. Hasil uji normalitas data penelitian ini di uji terlebih dahulu masing-masing kelompok dapat dilakukan uji prasyarat analisis yaitu dilihat pada tabel 4 .

uji normalitas dan uji homogenitas 


\section{Badrul Wajdi - Pemanfaatan Media Power Point ...}

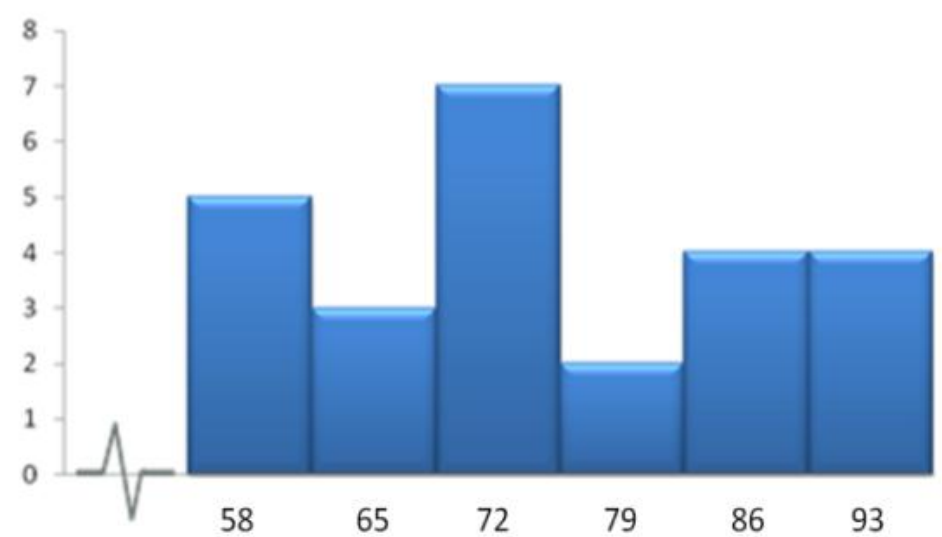

Gambar 1. Histogram data kelas eksperimen

Tabel 3. Distribusi frekuensi kelas kontrol

\begin{tabular}{|c|c|c|}
\hline Interval Nilai & Titik Tengah & Frekuensi \\
\hline $45-51$ & 48 & 4 \\
\hline $52-58$ & 55 & 4 \\
\hline $59-65$ & 62 & 2 \\
\hline $66-72$ & 69 & 4 \\
\hline $73-79$ & 76 & 7 \\
\hline $80-86$ & 83 & 4 \\
\hline \multicolumn{2}{|c|}{ Jumlah } \\
\hline
\end{tabular}

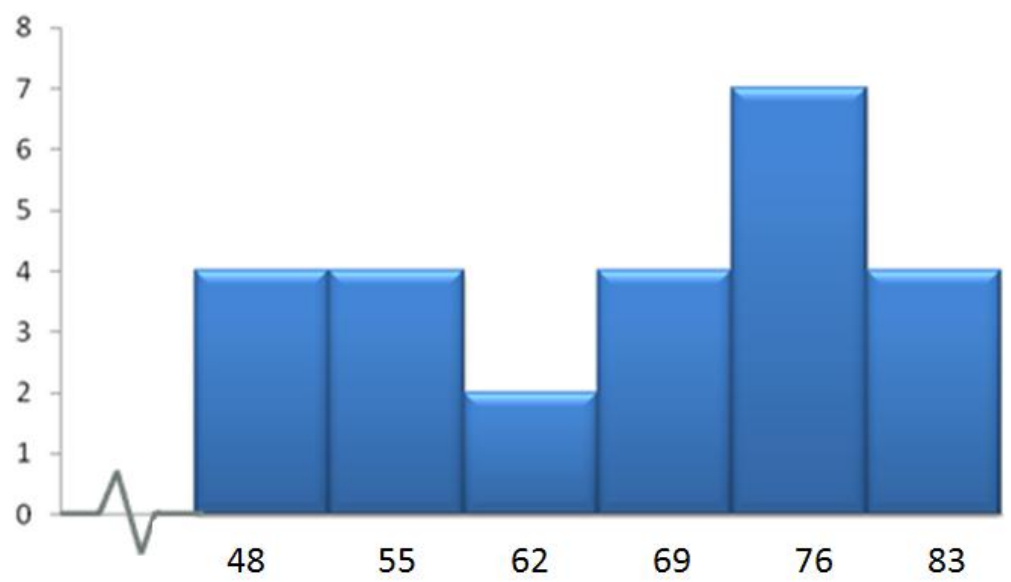

Gambar 2. Histogram data post tes kelas kontrol 
Badrul Wajdi - Pemanfaatan Media Power Point ...

Tabel 4. Uji Normalitas Data Post-Test

\begin{tabular}{|c|c|c|c|}
\hline Kelas & $\chi^{2}{ }_{\text {hitung }}$ & $\chi_{\text {tabel }}^{2}$ & Kriteria \\
\hline Post-test Eksperimen & 10,3806 & 11,070 & Terdistribusi normal \\
\hline Post-test Kontrol & 8.2756 & 11,07 & Terdistribusi normal \\
& & & \\
\hline
\end{tabular}

Hasil perhitungan uji homogenitas post test diperoleh $\chi^{2}$ hitung sama dengan 0,110 dan $\chi^{2}$ tabel sama dengan 3,481 Berdasarkan kriteria yang ada yaitu apabila $\chi^{2}$ hitung $<\chi_{\text {tabel }}^{2}$ maka kelompok tersebut berasal dari sampel homogen.

Setelah terpenuhi persyaratan analisis tersebut, maka dapat dilakukan uji hipotesis untuk melihat apakah hipotesis yang telah diajukan diterima atau ditolak. Dengan $t_{\text {tabel }}$ pada taraf signifikan 5\% (0,05). Dari perhitungan data dilakukan bahwa nilai $\mathrm{t}_{\text {hitung }}=2,065$ sedangkan $\mathrm{t}_{\text {tabel }}=$ 1,684 sedangkan dari data tersebut dapat disimpulkan bahwa nilai $t_{\text {hitung }}>$ dari $t_{\text {tabel}}$, dengan kata lain Ho ditolak dan Ha diterima. Jadi ada pengaruh pemanfaatan media power point dalam pembelajaran fisika dengan pendekatan konstruktivisme terhadap prestasi belajar fisika siswa pada materi zat dan wujudnya.

$$
\text { Pembelajaran }
$$

dengan menggunakan media power point merupakan salah satu media berbasis audio visual yang dirancang untuk meningkatkan prestasi belajar siswa pada pelajaran fisika khususnya materi wujud zat. Dimana media audio visual adalah penggabungan antara penggunaan suara (audio) dan sekaligus gambar, photo dan lukisan (visual) yang menunjukkan tampaknya sesuatu benda serta menunjukkan hubungan-hubungan ruang antara unsur-unsur dalam isi materi secara bersamaan seperti pada film, video dan televisi atau media audio visual adalah media yang mempunyai unsur suara dan unsur gambar. Nilai rata- rata pada kelompok eksperimen 74,52 dari skor maksimal 95 dan skor minimal 55 dan nilai rata-rata kelompok kontrol 67,04 dari skor maksimal 85 dan skor minimal 45. sehingga dapat diketahui bahwa penggunaan media power 
point mempunyai pengaruh yang posistif terhadap hasil belajar siswa khususnya pada sub pokok materi wujud zat.

Dari hasil pengujian hipotesis, ternyata hipotesis alternatif (Ha) diterima. Pengujian hipotesis dalam penelitian menggunakan uji $\mathrm{t}$ dan dari perhitungan statistiknya diperoleh $t_{\text {hitung }}=2,065$ selanjutnya harga $t_{\text {hitung }}$ tersebut dibandingkan dengan harga $\mathrm{t}_{\text {tabel }}$ dengan taraf signifikan $5 \%$ diperoleh $\mathrm{t}_{\text {tabel }}=1,684$ maka $\mathrm{t}_{\text {hitung }}>$ $t_{\text {tabel }}$ yaitu 2,065>1,684. Maka hasil pengujian hipotesis adalah Ho ditolak dan Ha diterima.

Dari hasil pengujian tersebut terlihat bahwa pengajaran dengan menggunakan media power point dapat menghasilkan prestasi belajar fisika yang lebih baik dibandingkan dengan media konvensional terhadap siswa. Dengan demikian pengajaran dengan menggunakan media power point lebih efektif daripada pengajaran secara konvensional terhadap prestasi belajar siswa dan berpengaruh positif terhadap prestasi belajar siswa.

\section{PENUTUP}

\section{Kesimpulan}

Berdasarkan data hasil penelitian dan pembahasan pada bagia sebelumnya maka dapat disimpulkan bahwa ada pengaruh pemanfaatan media power point dalam pembelajaran fisika dengan pendekatan konstruktivisme terhadap prestasi belajar fisika siswa pada materi zat dan wujudnya. Pembelajaran menggunakan media power point menghasilkan prestasi belajar fisika yang lebih baik dibandingkan dengan pembelajaran menggunakan media konvensional. Berdasarkan kesimpulan tersebut, sebagai masukan dan bahan pertimbangan maka di ajukan saran untuk guru fisika agar lebih memanfaatkan kemajuan teknologi dalam meningkatkan prestasi belajar siswa sehingga siswa dapat mengaplikasikan setiap materi dalam pelajaran fisika dalam kehidupan sehari-hari, kemudian untuk peneliti lain yang berminat untuk melakukan penelitian, disarankan untuk mengungkapkan faktor-faktor 
ataupun masalah-masalah yang belum

digunakan oleh orang lain.

\section{DAFTAR PUSTAKA}

Arsyad, Azhar. 2011. Media

Pembelajaran. Jakarta : Rajawali.

Budiningsih. 2005. Belajar dan pembelajaran. Jakarta: Rineka Cipta

Oemar Hamalik. 2001. Proses Belajar Mengajar. Jakarta: PT Bumi Aksara 